\title{
Supplement to: Assessment of Parameters Describing Representativeness of Air Quality in-situ Measurement Sites
}

\author{
S. Henne, D. Brunner, D. Folini, S. Solberg, J. Klausen, B. Buchmann
}

\section{S1 Model inter-comparison details}

FLEXPART and COSMO LPDM generated output on different grids. To compare the output the COSMO residence times where interpolated onto the $0.1^{\circ}$ by $0.1^{\circ}$ grid of the nested FLEXPART output domain using bicubic interpolation of log-transformed residence times (to avoid steep gradients). The interpolation was forced to conserve the total residence time between the two grids. (When instead interpolating the population and deposition fields onto the COSMO LPDM grid, catchment areas and parameters of representativeness did not differ from the aforementioned approach.) Furthermore, COSMO LPDM residence times were only available for the layer up to $500 \mathrm{~m}$ above model ground. To derive the catchment area as described above it was necessary to assume some vertical distribution of residence times. The total (including all vertical levels) residence time of each simulation and also of the total annual aggregate was known and was equal to the total length of backward integration minus 1.5 hours (due to successive release of particles within the first 3 simulated hours) times the number of simulations for the total annual residence time. Lacking any detailed knowledge of the vertical distribution we assumed that residence times outside the $500 \mathrm{~m}$ level would be situated in a layer reaching from 500 to $5000 \mathrm{~m}$ above model ground and the horizontal distribution would be proportional to the $500 \mathrm{~m}$ layer. Changing the upper boundary of $5000 \mathrm{~m}$ to lower levels resulted in slightly smaller catchment areas and vice versa. Overall the influence of this upper boundary was small.

The total annual footprints as derived from both simulations (not shown) compare generally well. Structure and extent of the footprints and catchment areas were similar. Due to the limited horizontal domain COSMO LPDM footprints were cropped at the model boundaries. Individual structures like surface flow blocking by the Alps (as seen for Donon, but also for more distant sites Cabauw and Harwell) or flow around the northern side of the Pyrenees (as seen for Mahon) are clearly visible in both simulations. A closer examination of the footprints revealed a number of small scale features that are only visible in the COSMO LPDM simulations. This can be attributed to the higher resolution of wind input data used for these calculations. Furthermore, the model topography in COSMO is less smoothed in comparison to the FLEXPART input data allowing near surface flow to be represented in more detail.

These general observations were supported by parameters describing the catchment geometry. While the total surface areas of catchments, $A$, agreed fairly well between the models (Figure S1a), the circularity, $c$, strongly differed (Figure S1b). Circularity describes the deviation of a shape from a circle by the ratio between the shape's surface area, $A$, and the surface area of a circle with the same perimeter as the length of the contour line, $L$, enclosing the shape $c=4 \pi A / L^{2}$. The total residence time within the catchment area was generally larger for the COSMO LPDM simulations (Figure S1c). FLEXPART total residence times were on average (for the 5 sites) 12, 19, and $17 \%$ smaller than the ones obtained by COSMO LPDM for the 12, 24 and 48 hour catchment areas, respectively. Only the site Mahon (ES06), which is situated on of the Balearic Island of Minorca in the Mediterranean, showed better agreement for the 12 and 24 hour catchment areas and even larger FLEXPART total residence times for the 48 hour catchment area.

The relative total residence time difference depended on the distance from the receptor as indicated 
by average relative differences by distance from the receptor (Figure S2). Up to a distance of about $500 \mathrm{~km}$ COSMO LPDM residence times were up to $50 \%$ larger than FLEXPART's for 4 of the 5 inter-comparison sites for the 24 hour footprint (Figure S2b). Only the site Mahon showed little residence time differences within this distance range. From 500 to $1500 \mathrm{~km}$ distance from the receptor differences first decreased, followed by positive differences (FLEXPART larger) for distances larger than $1000 \mathrm{~km}$. The site Mahon again showed behaviour opposite to the other sites. The differences reached maxima of about $100 \%$ for the sites Cabauw and Kosetice at a distance of 1500 and $2000 \mathrm{~km}$, respectively. Differences for the sites Donon and Harwell remained smaller. The strong drop of relative differences for the largest distances should not be over interpreted, since total residence times in this distance range were small. Up to a distance of about $1200 \mathrm{~km}$ total residence times decreased with $1 / r^{2}$ in both models (not shown). As well for the 12 hour footprint the COSMO LPDM showed about $50 \%$ larger residence times up to $500 \mathrm{~km}$ from the receptors, while at larger distances FLEXPART residence times were strongly enhanced (Figure S2a). Residence time differences within the 48 hour footprints were reduced compared to 12 and 24 hour footprints (Figure S2c), however, the general picture of larger COSMO LPDM residence times up to a distance of about $1000 \mathrm{~km}$ and larger FLEXPART residence times beyond remained evident. In all cases residence times for Mahon (ES06) showed opposite behaviour as compared to the other sites. The most likely cause of the apparent differences in residence times is the treatment of vertical dispersion in both models. In FLEXPART vertical dispersion seems to be stronger, leading to generally lower surface residence times and also to faster horizontal dispersion since horizontal transport at higher altitudes is faster. For the island site Mahon the differences were distinctly smaller, suggesting that vertical dispersion over the ocean is more similar in the models. A more detailed analysis of the causes of the observed residence time differences should be undertaken for future studies but is beyond the scope of this manuscript.

In order to compare parameters of representativeness that were derived by the two different models and contain the total annual residence time, it was necessary to scale the results of one of the models. This was achieved by multiplying the COSMO LPDM total residence times by the FLEXPART to COSMO LPDM total residence time ratio derived from the inter-comparison that resulted to 0.88 , 0.81 and 0.83 for 12,24 and 48 hour catchment areas, respectively. The horizontal variability of this ratio was not not taken into account. Scaled COSMO LPDM residence times are shown in Figure S1c as well. While the spearman rank correlation coefficients (given in the figure legend) did not improve with this conversion, the root mean square difference between the estimated total residence times decreased by 60,61 and $26 \%$ for the 12,24 and 48 hour catchment areas, respectively.
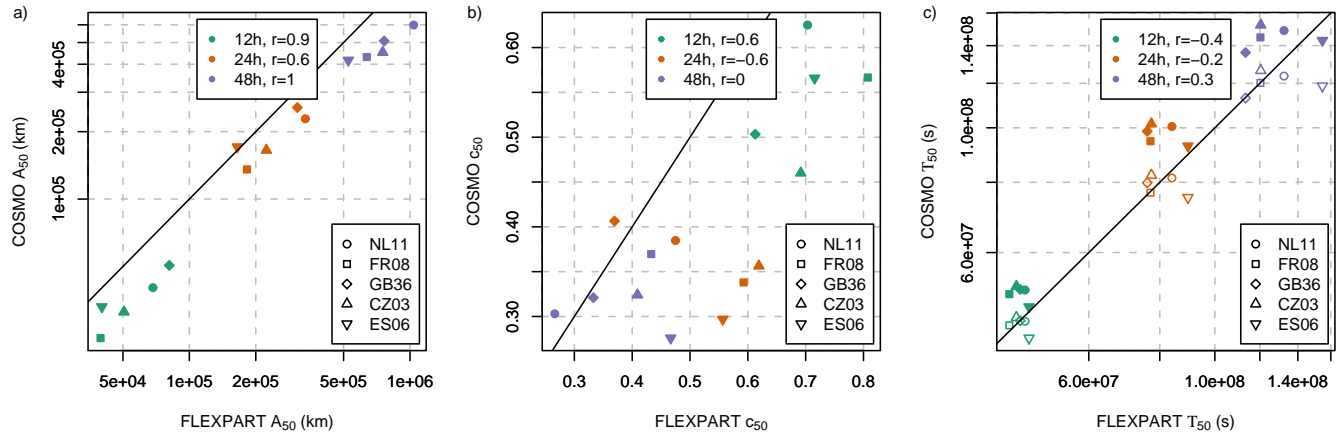

Fig. S1: Catchment geometry parameters, (a) area $A$, (b) circularity $c$ and (c) total annual residence time $T$ as derived by COSMO LPDM versus those derived by FLEXPART. In (c) solid symbols represent original COSMO LPDM results, empty symbols represent parameters derived with scaled COSMO LPDM residence times. $r$ gives the Spearman rank correlation coefficient. 

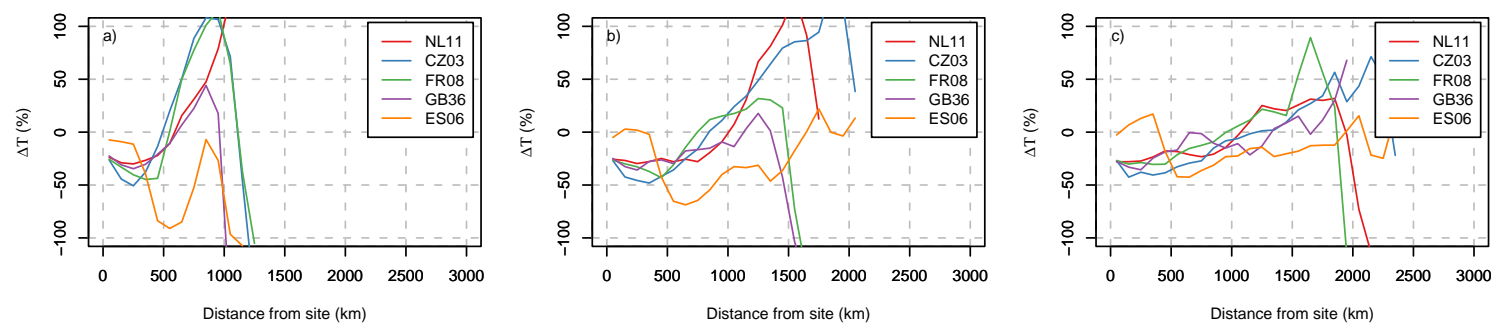

Fig. S2: Relative difference of total annual residence times, FLEXPART - COSMO LPDM, versus distance from the receptor site for (a) $12 \mathrm{~h}$, (b) $24 \mathrm{~h}$ and (c) $48 \mathrm{~h}$ integration time.

\section{S2 Transport model validation}

Surface footprints can be combined with emission fields to derive mixing ratios of the emitted substance at the receptor site (e.g. Folini et al., 2008). To estimate the performance of our transport models we derived $\mathrm{CO}$ mixing ratios at those receptor sites where $\mathrm{CO}$ measurements are available. $\mathrm{CO}$ was chosen because it can be assumed to be inert within 5 days of transport. Two different $\mathrm{CO}$ emission inventories were used. Firstly the European Monitoring and Evaluation Programme (EMEP) anthropogenic CO emissions (Tarrason et al., 2007) for the reference year 2005 on a $0.5^{\circ}$ by $0.5^{\circ}$ grid (available from http://www.emep.int) were mapped onto the FLEXPART domains. Secondly, the Emission Database for Global Atmospheric Research (EDGAR) CO emissions (Version 3.2 FT) (Olivier and Berdowski, 2001), comprising both anthropogenic and natural sources, for the reference year 2000 on a $1^{\circ}$ by $1^{\circ}$ grid was used. Total emissions for the nested FLEXPART domain differed substantially between the two inventories (EMEP $35 \mathrm{Mt} \mathrm{yr}^{-1}$, EDGAR $52 \mathrm{Mt} \mathrm{yr}^{-1}$ ), probably explained by decreasing emissions since 2000 (EMEP 2000: $40 \mathrm{Mt} \mathrm{yr}^{-1}$ ) and lacking biomass burning emissions in the EMEP inventory. In order to compare the observations with the simulated $\mathrm{CO}$ mixing ratios that only represent the CO accumulated within the last 60 and 120 hours before arrival, respectively, a background had to be subtracted from the observations. Background levels were derived using the non-parametric fit and filtering method suggested by Ruckstuhl et al. (2009).

The results of the model performance are displayed in Figure S3 as a Taylor plot (Taylor, 2001) presenting model skill in terms of correlation, variance and normalised root mean square difference (NRMSD), defined here as $R M S D(r, s) / \sigma_{r}$. When 3-hourly mean simulations were compared with average observations, correlation coefficients in the range of 0.2 to 0.75 were achieved, while NRMSD were on average about 0.8 (Figure S3a). Correlations improved slightly, $r=0.4-0.85$, when diurnal averages were considered instead of 3-hourly values (Figure S3b). However, NRMSD remained large. When EDGAR emissions were used instead of EMEP emissions, FLEXPART simulations showed generally larger variance due to the larger total EDGAR emissions. However, model skill in terms of correlation and NRMSD did not improve for either 3-hourly or daily values, respectively. Best model skill was achieved for coastal sites that only experience infrequent long-range transport of pollutants (Mace Head (IE31), Weybourne (WEY)). Mountain sites (simulated with COSMO LPDM) showed weak $(r<0.4)$ (Sonnblick (AT34), Pic du Midi (PDM), Observatoire Haute Provence (OHP ), and Jungfraujoch $(\mathrm{CH} 01))$ to moderate $(0.4<r<0.6)$ correlations (Donon (FR08) and Puy de Dome ( PUY)). Additional simulations with FLEXPART for Jungfraujoch (CH01) showed slightly improved correlations, however, the seasonality of the observed diurnal cycle (not shown) was not as well reproduced as it was by the COSMO LPDM simulations. We conclude that the COSMO LPDM is able to capture part of the summer-time thermally driven pollution export from the ABL above complex terrain (mountain venting, e.g. Henne et al., 2004) and therefore its application to sites in complex terrain in this study is justified.

Correlations and NRMSD strongly improved with integration time, levelling off at integration times larger than 60 hours (not shown). The simulations improved only slightly when time dependent emissions applying a seasonal, weekly and diurnal cycle as suggested by Folini et al. (2009) were 
a)

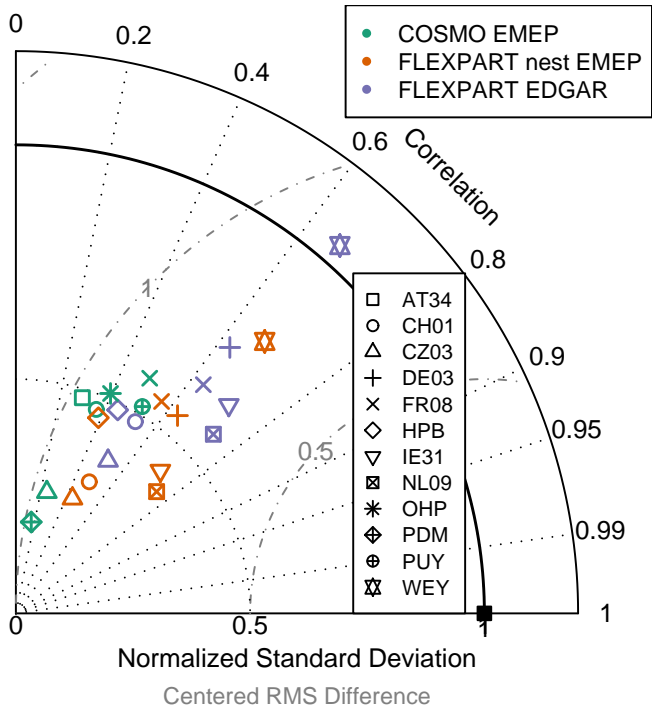

b)

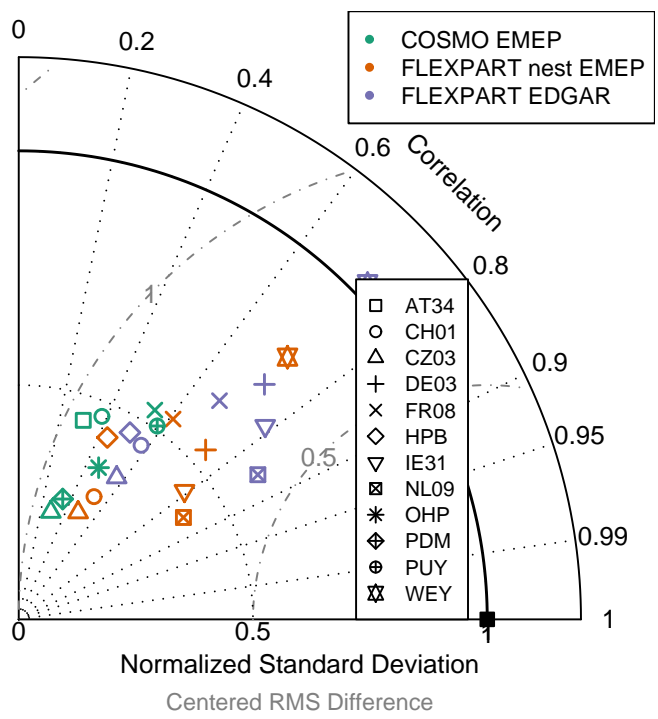

Fig. S3: Taylor plot of (left) 3-hourly and (right) daily mean simulated and observed above background $\mathrm{CO}$ mixing ratios for all sites where measurements were available and for different emission inventories. The backward integration time was $120 \mathrm{~h}$ and $60 \mathrm{~h}$ for FLEXPART and COSMO LPDM simulations, respectively.

considered .

\section{S3 Alternative categorization}

As for the reference categorisation, presented in the main text, the categories obtained from parameters of representativeness in the surrounding can be discussed in context of category by category distribution of these parameters (Figure S4) and the location of the sites (Figure S5). The estimated categories can be described as follows:

- The first category comprises 10 sites, that are mainly situated in flat terrain both close to the coast but also at continental locations. Furthermore, the sites are characterised by moderate to large total population and variability and large deposition velocities. Here we refer to this category as rural.

- The second category (7 sites) consists of sites at the coast with moderate total population and variability, a large spread in mean deposition velocities and large variability in deposition velocities. This category can be identified as rural coastal.

- The third category comprises 7 sites that clearly showed the largest population in the $10 \mathrm{~km}$ surroundings and we therefore describe them as rural polluted. Mean deposition values were moderate but its variability was large and most of the sites are slightly elevated.

- The 6 sites in the fourth category showed very small total population and variability especially for the $50 \mathrm{~km}$ surrounding, while there was large within-group scatter for the deposition parameters and also the altitude differences. These sites can be identified as remote coastal or highaltitude sites.

- The 4 remaining sites are all situated at isolated peaks at high altitude as indicated by large altitude differences. All other parameters were around average. 


\section{References}

Folini, D., Ubl, S., and Kaufmann, P.: Lagrangian particle dispersion modeling for the high Alpine site Jungfraujoch, J. Geophys. Res., 113, D18111, doi:10.1029/2007JD009558, 2008.

Folini, D., Kaufmann, P., Ubl, S., and Henne, S.: Region of infuence of 13 remote European measurement sites based on modeled CO mixing ratios, Journal of Geophysical Research, D08307, doi:10.1029/2008JD011125, 2009.

Henne, S., Furger, M., Nyeki, S., Steinbacher, M., Neininger, B., De Wekker, S. F. J., Dommen, J., Spichtinger, N., Stohl, A., and Prevot, A. S. H.: Quantification of topographic venting of boundary layer air to the free troposphere, Atmospheric Chemistry and Physics, 4, 497-509, 2004.

Olivier, J. and Berdowski, J.: Global Emissions Sources and Sinks, in: The Climate System, edited by Berdowski, J., Guicherit, R., and Heij, B., pp. 33-78, Balkema Publishers/Swets \& Zeitlinger Publishers, Lisse, The Netherlands, 2001.

Ruckstuhl, A., Henne, S., Reimann, S., and Hüglin, C.: Estimation of background concentrations of atmospheric trace gases using robust local regression, Atmospheric Chemistry and Physics Discussions, in preparation, 2009.

Tarrason, L., Fagerli, H., Jonson, J. E., Simpson, D., Benedictow, A., Klein, H., Vestreng, V., Aas, W., and Hjelbrekke, A.-G.: Transboundary Acidification, Eutrophication and Ground Level Ozone in Europe in 2005, Tech. Rep. EMEP Report 1/2007, Norwegian Meteorological Institute, 2007.

Taylor, K. E.: Summarizing multiple aspects of model performance in a single diagram., Journal of Geophysical Research-Atmospheres, 106, 7183-7192, 2001. 
Tab. S1: Land cover categories, matched categories of Wesely (1989) surface deposition parameterization and resulting summer day-time $\mathrm{O}_{3}$ deposition velocities.

\begin{tabular}{|c|c|c|c|}
\hline GLC category & Description & Fraction of Wesely category & $\begin{array}{c}v_{d} \\
\left(\mathrm{~cm} \mathrm{~s}^{-1}\right)\end{array}$ \\
\hline 1 & $\begin{array}{l}\text { Tree Cover, broadleaved, ever- } \\
\text { green }\end{array}$ & $100 \%$ deciduous forest & 1.002 \\
\hline 2 & $\begin{array}{l}\text { Tree Cover, broadleaved, decidu- } \\
\text { ous, closed }\end{array}$ & $100 \%$ deciduous forest & 1.002 \\
\hline 3 & $\begin{array}{l}\text { Tree Cover, broadleaved, decidu- } \\
\text { ous, open }\end{array}$ & $\begin{array}{l}70 \% \text { deciduous forest, } 30 \% \\
\text { mixed forest }\end{array}$ & 0.927 \\
\hline 4 & $\begin{array}{l}\text { Tree Cover, needle-leaved, ever- } \\
\text { green }\end{array}$ & $100 \%$ coniferous forest & 0.621 \\
\hline 5 & $\begin{array}{l}\text { Tree Cover, needle-leaved, decid- } \\
\text { uous }\end{array}$ & $100 \%$ coniferous forest & 0.621 \\
\hline 6 & Tree Cover, mixed leaf type & $100 \%$ mixed forest & 0.753 \\
\hline 7 & $\begin{array}{l}\text { Tree Cover, regularly flooded, } \\
\text { fresh water ( \& brackish) }\end{array}$ & $100 \%$ mixed forest & 0.753 \\
\hline 8 & $\begin{array}{l}\text { Tree Cover, regularly flooded, } \\
\text { saline water }\end{array}$ & $100 \%$ mixed forest & 0.753 \\
\hline 9 & $\begin{array}{l}\text { Mosaic: Tree cover / Other nat- } \\
\text { ural vegetation }\end{array}$ & $\begin{array}{l}50 \% \text { range land, } 50 \% \text { mixed for- } \\
\text { est }\end{array}$ & 0.849 \\
\hline 10 & Tree Cover, burnt & $100 \%$ barren land/desert & 0.253 \\
\hline 11 & $\begin{array}{l}\text { Shrub Cover, closed-open, ever- } \\
\text { green }\end{array}$ & $\begin{array}{l}50 \% \text { range land, } 50 \% \text { mixed for- } \\
\text { est }\end{array}$ & 0.849 \\
\hline 12 & $\begin{array}{l}\text { Shrub Cover, closed-open, decid- } \\
\text { uous }\end{array}$ & $\begin{array}{l}50 \% \text { range land, } 50 \% \text { mixed for- } \\
\text { est }\end{array}$ & 0.849 \\
\hline 13 & Herbaceous Cover, closed-open & $100 \%$ range land & 0.946 \\
\hline 14 & $\begin{array}{l}\text { Sparse Herbaceous or sparse } \\
\text { Shrub Cover }\end{array}$ & $\begin{array}{l}50 \% \text { range land, } 50 \% \text { barren } \\
\text { land/desert }\end{array}$ & 0.599 \\
\hline 15 & $\begin{array}{l}\text { Regularly flooded Shrub and/or } \\
\text { Herbaceous Cover }\end{array}$ & $100 \%$ non-forested wetland & 1.177 \\
\hline 16 & Cultivated and managed areas & $100 \%$ agriculture & 1.380 \\
\hline 17 & $\begin{array}{l}\text { Mosaic: Cropland / Tree Cover } \\
\text { / Other natural vegetation }\end{array}$ & $\begin{array}{l}33 \% \text { agriculture, } 33 \% \text { range } \\
\text { land, } 33 \% \text { deciduous forest }\end{array}$ & 1.109 \\
\hline 18 & $\begin{array}{l}\text { Mosaic: Cropland / Shrub or } \\
\text { Grass Cover }\end{array}$ & $\begin{array}{l}100 \% \text { mixed agriculture and } \\
\text { range land }\end{array}$ & 1.012 \\
\hline 19 & Bare Areas & $100 \%$ barren land/desert & 0.253 \\
\hline 20 & Water Bodies (natural/artificial) & $100 \%$ water & 0.053 \\
\hline 21 & Snow and Ice (natural/artificial) & $100 \%$ water & 0.053 \\
\hline 22 & $\begin{array}{l}\text { Artificial surfaces and associated } \\
\text { areas }\end{array}$ & $100 \%$ urban land & 0.253 \\
\hline 23 & Irrigated Agriculture & $100 \%$ agriculture & 1.380 \\
\hline
\end{tabular}



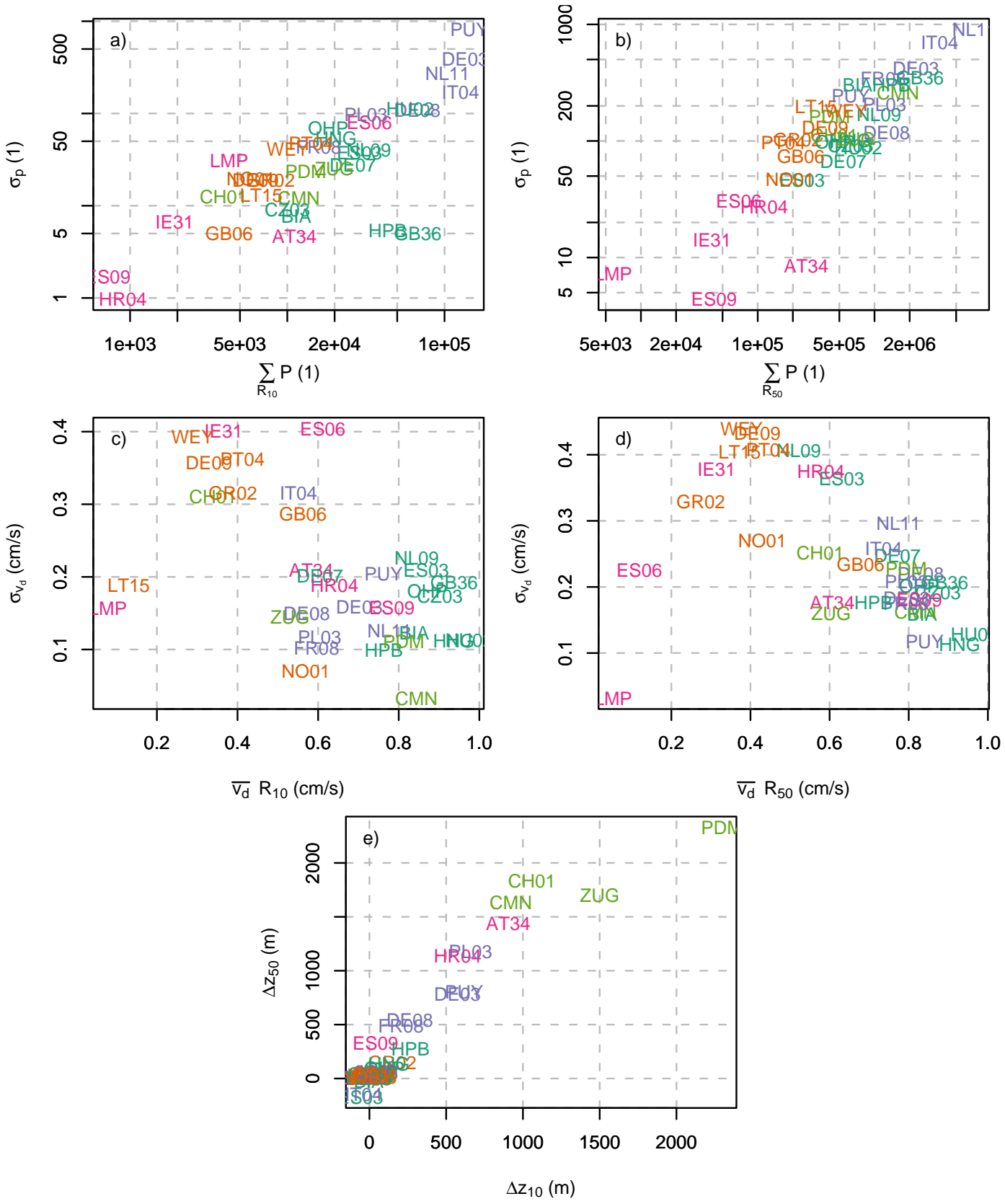

Fig. S4: Scatter plots of population parameters $\sigma_{p}$ versus $\sum P$ for (a) $10 \mathrm{~km}$, (b) $50 \mathrm{~km}$ surroundings, deposition parameters $\sigma_{v_{d}}$ versus $\bar{v}_{d}$ for (c) $10 \mathrm{~km}$, (d) $50 \mathrm{~km}$ surroundings and (e) altitude difference $\Delta z 50 \mathrm{~km}$ versus $10 \mathrm{~km}$. The colours refer to the categories identified by the site categorisation, compare Fig. S5. 


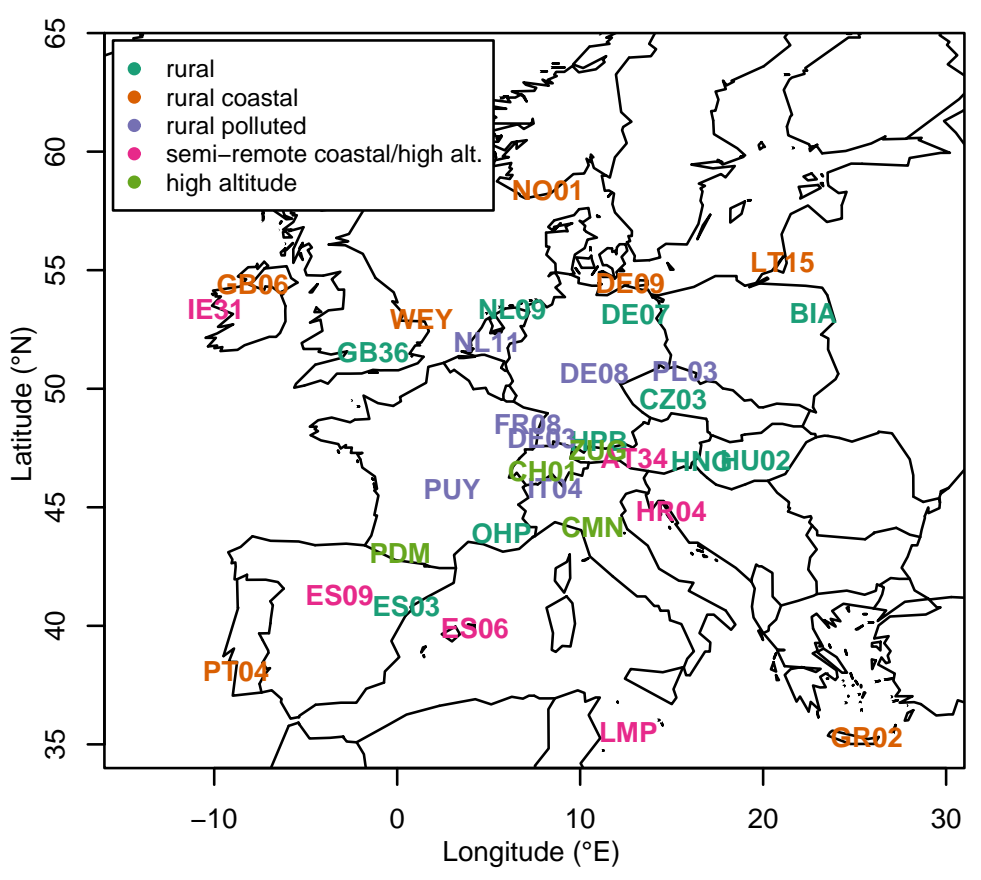

Fig. S5: Map of sites showing categorisation as obtained from clustering of parameters of representativeness in the surrounding areas.

Tab. S2: Contingency table of categorisation using catchment areas (rows) and circular surroundings (columns). Numbers in bold indicates sites that were categorised into similar groups by both approaches.

\begin{tabular}{cccccc}
\hline & high altitude & rural & rural coastal & rural polluted & $\begin{array}{c}\text { semi-remote } \\
\text { coastal/high alt. }\end{array}$ \\
\hline polluted rural & 0 & 2 & 1 & $\mathbf{2}$ & 0 \\
remote coastal/high alt. & $\mathbf{2}$ & 0 & 3 & 0 & 2 \\
rural & 0 & $\mathbf{6}$ & 0 & 4 & 0 \\
rural coastal & 0 & 1 & $\mathbf{3}$ & 0 & 0 \\
semi-remote & & & & & $\mathbf{2}$ \\
coastal/high alt. & $\mathbf{2}$ & 1 & 0 & 1 & 2 \\
very remote coastal & 0 & 0 & 0 & 0 & \\
\hline
\end{tabular}



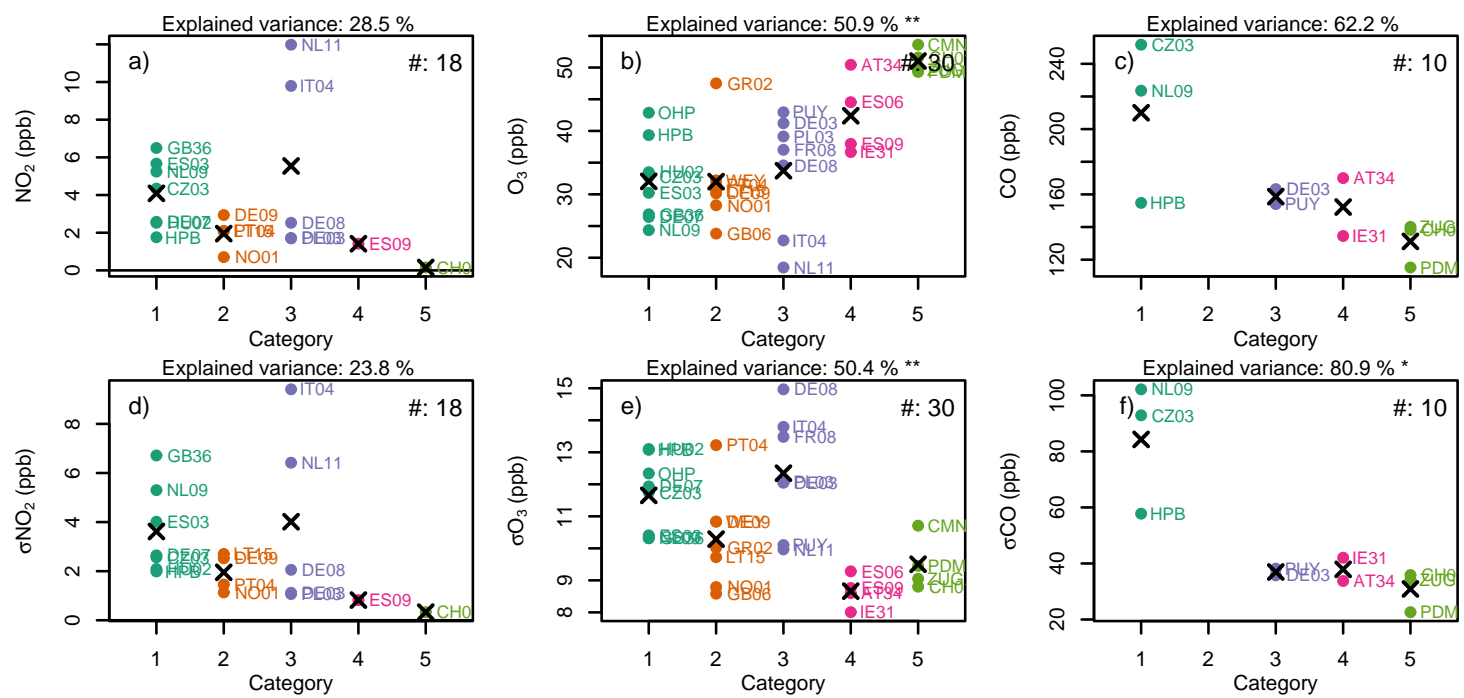

Fig. S6: Median (upper row) and standard (lower row) deviation of observed mixing ratios of (a, d) $\mathrm{NO}_{2}$, (b, e) $\mathrm{O}_{3}$, (c, f) $\mathrm{CO}$ by site plotted versus site category as derived from parameters of the surrounding areas. Black crosses represent the category mean. The star notation in each panel represents the confidence level of differences between category means as derived from ANOVA f statistics (*: $\left.\alpha<0.1,{ }^{* *}: \alpha<0.05,{ }^{* * *}: \alpha<0.01\right)$. 